\title{
ACTIVE SMOKING AND ASSOCIATED BEHAVIOURAL RISK FACTORS BEFORE AND DURING PREGNANCY - PREVALENCE AND ATTITUDES AMONG NEWBORNS' MOTHERS IN MURES COUNTY, ROMANIA
}

\author{
Florina Ruta', Calin Avram², Septimiu Voidăzan³, Claudiu Mărginean ${ }^{4}$, Vladimir Bacârea ${ }^{5}$, Zoltán Ábrám 6 , Kristie \\ Foley $^{7}$, Andrea Fogarasi-Grenczer ${ }^{8}$, Melinda Pénzes ${ }^{9}$, Monica Tarcea ${ }^{1}$ \\ ${ }^{1}$ Department of Community Nutrition and Food safety, University of Medicine and Pharmacy, Tirgu-Mures, Romania \\ ${ }^{2}$ Department of Medical Informatics and Biostatistics, University of Medicine and Pharmacy, Tirgu-Mures, Romania \\ ${ }^{3}$ Department of Epidemiology, University of Medicine and Pharmacy, Tirgu-Mures, Romania \\ ${ }_{4}^{4}$ Department of Obstetrics and Gynaecology, University of Medicine and Pharmacy, Tirgu-Mures, Romania \\ ${ }^{5}$ Department of Research Methodology, University of Medicine and Pharmacy, Tirgu-Mures, Romania \\ ${ }^{6}$ Department of Hygiene, University of Medicine and Pharmacy, Tirgu-Mures, Romania \\ ${ }^{7}$ Department of Social Sciences and Health Policy, Wake Forest School of Medicine, Winston-Salem, NC, USA \\ ${ }^{8}$ Department of Family Care and Methodology, Faculty of Health Sciences, Institute of Public Health, Semmelweis University, Budapest, Hungary \\ ${ }^{9}$ Faculty of Medicine, Institute of Public Health, Semmelweis University, Budapest, Hungary
}

\section{SUMMARY}

Background and Aim: Smoking before, during and after pregnancy leads to detrimental outcomes on maternal and foetal health and represents an important public health issue. This study aims to evaluate the prevalence and correlates of smoking before and during pregnancy in a sample of Romanian women.

Methods: A cross-sectional survey was conducted among mothers $(\mathrm{N}=1,278)$ in three maternity hospitals in Tirgu-Mures, Romania, immediately after childbirth, in 2014. We evaluated the prevalence of smoking before and during pregnancy and used binary logistic regression to assess the influence of socio-demographics and other health behaviour factors in three groups of women: non-smoking pregnant women, women who continued smoking during pregnancy, and smokers who quit during pregnancy.

Results: $30 \%$ of the interviewed mothers were smokers prior to pregnancy, of whom $43.3 \%$ continued smoking during pregnancy. Women with a family income of less than 100 Euro/month $(\mathrm{OR}=3.01,95 \% \mathrm{Cl}: 1.02-8.83)$ and those who were unemployed $(\mathrm{OR}=13.2,95 \% \mathrm{Cl}$ : 3.90-44.79) had increased odds of continued smoking versus quitting during pregancy in multivariable analyses. Women who continued smoking during pregnancy were also more likley to be of lower socioeconomic status than never smokers (OR=14.1,95\% Cl: 4.97-39.6).

Conclusions: A high percentage of women of reproductive age smoke and continue to smoke despite their knowledge about risks of smoking during pregnancy. Smoking prior to and during pregnancy is predominantly associated with lower socioeconomic status. Women with limited economic means should be a high priority target group for smoking cessation interventions.

Key words: smoking, pregnancy, risk factor, cessation, intervention

Address for correspondence: C. Avram, University of Medicine and Pharmacy,38 Gh. Marinescu street, 540139 Tirgu-Mures, Romania. E-mail: avram.calin@umftgm.ro

http://dx.doi.org/10.21101/cejph.a4559

\section{INTRODUCTION}

Smoking is one of the major modifiable risk factors, responsible for the premature death of nearly 6 million people worldwide and considerable economic costs to health systems (1-3). Among women, smoking is associated with an increased risk of breast cancer, cervical cancer, ovarian cancer, infertility, and early menopause (4). Smoking is of special concern to pregnant women, as this behaviour affects not only the mother's health, but also the health of the foetus (5). Serious complications include the risk of placental abruption, anaemia, small for gestational age newborns, premature birth, eclampsia, and placenta previa (4, 6-8).

Pregnancy represents a major life event that requires a mother to assume a healthy lifestyle to increase the probability of healthy development of the foetus and long-term well-being of her child. Despite the importance of good health for herself and her children, smoking during pregnancy remains a global problem, especially in Europe (10).

Borland et al. (11) has estimated that $10 \%$ to $27 \%$ of pregnant women in the European Union continue smoking during pregnancy. In Central and Eastern Europe, especially in the former 
communist countries, smoking prevalence increased in the 1990s, particularly among women $(7,12)$, with the exception of Croatia and the Czech Republic $(10,13)$. In a nationally representative study conducted in Romania by the Ministry of Health in 2003, $27 \%$ of women between the ages of 15-44 years were current smokers (14), despite a declining trend of smoking among the general population in Romania from $35 \%$ in 2000 to $26.7 \%$ in 2011 (12). Smoking trends among females of reproductive age have stabilized in the past ten years. In 2007, smoking prevalence among women was $34.8 \%$ for females aged $15-24$ and $32.9 \%$ for females aged 25-39 years. In 2011, the prevalence of smoking was estimated to be $36.3 \%$ among women $25-44$ years old suggesting a potential increasing rate of smoking among women (14). Munteanu et al. (15) reported that $24 \%$ of 160 pregnant women in maternity wards in Bucharest were smokers, consistent prevalence with the findings by Moga and Preda (9), who reported that $24 \%$ of pregnant women were smokers in a much larger sample $(\mathrm{n}=23,000)$. The study by Meghea et al. conducted in the Transylvanian region of Romania showed that $41 \%$ of investigated women smoked before pregnancy, $15 \%$ continued to smoke during pregnancy and $26 \%$ quit upon finding out about the pregnancy (16).

Lack of national data on smoking during pregnancy in low and middle income countries limits the capacity to compare data from high income countries to low income ones (15).

Tobacco prevention and cessation campaigns should focus on improving pregnancy outcomes in lower middle income countries in the future $(3,17)$. Therefore, the objective of our study was to identify the relationship between socio-demographic and health behaviour variables in pregnant women from Mures County, Romania, who continued to smoke or quit smoking during their pregnancy. This project was undertaken as formative research for the development of a locally-tailored intervention to promote cessation among pregnant women who smoke.

\section{MATERIALS AND METHODS}

\section{Setting and Population}

We conducted a cross-sectional study on 1,278 women who had just given birth and were in the hospital post-delivery under routine care and observation. The hospitals are located in TirguMures, a city within the Transylvanian region in Romania with a population of 140,000 citizens. The hospitals predominantly serve residents within the city, but rural residents in surrounding villages also use the hospitals for delivery. Two hospitals are state-run and available to all pregnant women regardless of their ability to pay. The third clinic is private, and serves persons who can pay or have private insurance.

The research was approved by the Ethics Committee at the University of Medicine and Pharmacy, Tirgu-Mures as part of a larger study on building capacity for tobacco research in Romania. We obtained written informed consent from our subjects and all data were anonymous. Data were collected during a 9-month period (2013-2014) by trained data collectors who conducted interviews with the participants. Survey response rate was $91 \%$. Non-participation was due to refusal of the patient $(8.6 \%)$ or due to medical complications that prevented their involvment (1\%).

\section{Measurements}

Descriptive statistics were used to determine the prevalence of smoking during pregnancy and to estimate the prevalence of potential risk factors for continued smoking.

\section{Socio-demographic Characteristics of Respondents}

We measured the following characteristics: age, level of education ( $\leq 8$ grades, high-school, college and university), selfidentified ethnicity (Romanian, Hungarian, Roma and other), employment status prior to delivery (employed vs. unemployed, the latter including homemakers without income), and family income (under 50 Euro, 50-100 Euro, 100-300 Euro, 300-500 Euro, and 500+ Euro). We also assessed the lack of household facilities (central heating, water, gas stove, electricity, fridge, TV) vs. families with households that have such facilities as well as home ownership (no vs. yes). Place of birth was defined as a public or private hospital.

\section{Health Behaviour Variables}

Alcohol consumption was measured by asking "Number of alcohol-containing drinks consumed weekly during pregnancy?" Due to the limited number of affirmative responses, the data were dichotomized into "yes/no". Physical activity was asked by the following question: "How often did you exercise during pregnancy?": 2-3 times/week, daily.

\section{Smoking During Pregnancy}

Smoking during pregnancy was determined by several questions. First, women were asked, "Have you ever smoked a cigarette?" (yes/no). For anyone who had ever smoked, we asked, "What was the number of cigarettes smoked per day?". Also, the smokers were asked "What was your reaction to smoking after hearing the news that you are pregnant?" with the following answers: "I continued smoking in the same way", "I reduced the number of cigarettes", "I quit smoking immediately". Using these responses from these questions, women were classified into three groups: "non-smokers at the time of pregnancy", "smokers who continued smoking during pregnancy", and "smokers who quit".

\section{Neonatal Outcomes}

We assessed neonatal outcomes across the three groups of non-smokers, continuous smokers during pregnancy, and quitters. Variables included total weight of the newborn (in grams), percentage of women who gave birth to a low birth weight baby (defined as $<2,500 \mathrm{~g}$ ), and the percentage of women who gave birth preterm (defined as $<37$ weeks of gestation).

\section{Statistical Analysis}

Descriptive statistics were used to determine the prevalence of smoking and potential risk factors for continued smoking and quitting. Chi-square tests for nominal variables and ANOVA tests for continuous variables were used to assess the bivariate relationships between risk factors and smoking outcomes, unadjusted for potential confounding variables. 
Two multivariable logistic regression models were used to assess the odds of continued smoking versus quitting and the odds of continued smoking versus never smoking incorporating the socio-demographic and health behaviour measures into the model. Analyses were performed using SPSS v22.0 statistical software.

\section{RESULTS}

\section{Description of Sample}

Women were on average 29.47 years old (SD: 5.51), married, and had 2 children (range 1-9). The majority of respondents were self-identified as Romanian (64\%), followed by Hungarian (30.5\%), and Roma (5.5\%) (12). More than one-third of our subjects attained less than high school level of education. Approximately $24 \%$ of women were not working when they learned they were pregnant. Family incomes are low with more than one-forth of women reporting a monthly income of less than 100 Euros and one out of 10 families live in homes without basic facilities (e.g. plumbing, heating, etc.). Approximately $71 \%$ of the women gave birth in a public hospital.

\section{Smoking Status before and after Pregnancy}

Thirty percent of women participating on our project were smoking at the time they learned they are pregnant $(n=381$ women) with about half of them smoking fewer than 5 cigarettes per day (51.2\%). Only $2.36 \%$ of smokers reported smoking a pack or more of cigarettes per day prior to pregnancy. Among smokers, $56.69 \%$ quit immediately upon learning about their pregnancy. Of those who continued smoking $(n=165), 52.72 \%$ reduced the number of cigarettes smoked from the first to the third trimester. The remaining $47.72 \%$ continued to smoke at the same rate as before their pregnancy.

There were significant differences in birthweight of the newborns by mother's smoking status. Women who continued to smoke during pregnancy were significantly more likely to have a low birth weight baby compared to those who never smoked and who quit during pregnancy (never smoke $-3,136.59 \mathrm{~g}$, continued to smoke $-2,971.5 \mathrm{~g}$, quit $=3,172.04 \mathrm{~g} ; \mathrm{p}=0.001 / \mathrm{p}=0.002$ ).

In bivariate analyses, women who continued to smoke during pregnancy were significantly more likely to be self-identified as Roma, to be unmarried, have lower levels of education, have higher rates of unemployment, have lower incomes, lack utilities in the household, and more likely to consume alcohol and coffee while pregnant. They were also significantly more likely to have low birth weight babies than women of the other groups (never smokers and those who quit).

\section{Factors Associated with Smoking Status during Preg- nancy in Multivariable Models}

Table 2 presents the results of two logistic regressions: women who continued smoking during pregnancy $(n=165)$ vs. those

Table 1. Characteristics of pregnant women in Targu-Mures, Romania stratified by smoking status, and birth outcomes of their newborns

\begin{tabular}{|c|c|c|c|c|c|}
\hline \multirow[b]{2}{*}{ Variables } & \multicolumn{5}{|c|}{ Smoking status, $\mathrm{n}(\%)$} \\
\hline & $\begin{array}{c}\text { Non-smokers } \\
\text { at the time of } \\
\text { pregancy } \\
n=897\end{array}$ & $\begin{array}{l}\text { Smokers who con- } \\
\text { tinued to smoke } \\
\text { during pregnancy } \\
n=165\end{array}$ & $\begin{array}{l}\text { Smokers who quit } \\
\text { smoking during } \\
\text { pregnancy } \\
n=216\end{array}$ & p-value* & $\begin{array}{c}\text { Total } \\
N=1,278\end{array}$ \\
\hline \multicolumn{6}{|l|}{ Mothers } \\
\hline Age (years, mean, SD) & $29.70(4.81)$ & $28.06(6.83)$ & $29.62(4.28)$ & 0.002 & $29.47(5.51)$ \\
\hline Married & $780(86.95)$ & $99(60)$ & $177(81.94)$ & $<0.001$ & $1,056(82.62)$ \\
\hline Education below level of college & $273(30.43)$ & $111(67.27)$ & $81(37.50)$ & $<0.001$ & $465(36.38)$ \\
\hline Gave birth at public hospital & $633(70.56)$ & $120(72.72)$ & $150(69.44)$ & 0.78 & $903(70.65)$ \\
\hline Women who are not working for pay & $171(19.06)$ & $96(58.18)$ & $51(23.61)$ & $<0.001$ & $318(24.88)$ \\
\hline Self-identified Roma ethnicity & $37(4.12)$ & $24(14.54)$ & $9(4.16)$ & $<0.001$ & $70(5.5)$ \\
\hline Family income under 100 Euros/month & $183(20.40)$ & $78(47.27)$ & $54(25)$ & $<0.001$ & $315(24.65)$ \\
\hline $\begin{array}{l}\text { Lack of facilities in households (e.g., } \\
\text { water, sewer) }\end{array}$ & $63(7.02)$ & $51(30.91)$ & $21(9.72)$ & $<0.001$ & $135(10.56)$ \\
\hline Lack of home ownership & $87(9.70)$ & $27(16.36)$ & $30(13.89)$ & 0.006 & $144(11.27)$ \\
\hline Any alcohol consumption & $18(2.01)$ & $27(16.36)$ & $12(5.56)$ & $<0.001$ & $57(4.46)$ \\
\hline Daily coffee intake $>2$ cups & $48(5.35)$ & $30(18.18)$ & $24(11.11)$ & $<0.001$ & $102(7.98)$ \\
\hline Lack of daily moderate exercise & $537(59.87)$ & $111(67.27)$ & $129(59.72)$ & 0.09 & $777(60.80)$ \\
\hline \multicolumn{6}{|l|}{ Newborn } \\
\hline Weight (grams, mean, SD) & $3,136.59(673.51)$ & $2,971.5(743.89)$ & $3,172.09(528.74)$ & 0.007 & $2,121.56(662.97)$ \\
\hline Low birth weight (<2,500 grams) & $114(12.79)$ & $30(18.18)$ & $15(6.94)$ & 0.003 & $159(12.44)$ \\
\hline Pre-term (<37 weeks gestation) & $124(13.82)$ & $23(13.93)$ & $24(11.11)$ & 0.56 & $171(13.38)$ \\
\hline
\end{tabular}

${ }^{*}$ Chi-square used for bivariate comparisons of nominal data; ANOVA used for bivariate comparisons of continuous data, $p$-values reported 
Table 2. Factors associated with continued smoking (vs. quitting and vs. never smoking) among pregnant Romanian women

\begin{tabular}{|c|c|c|c|c|}
\hline & $\begin{array}{l}\text { OR } \\
\text { Those who continued to } \\
\text { smoke during pregnancy } \\
(n=165) \text { vs. smokers } \\
\text { who quit }(n=216)\end{array}$ & $95 \% \mathrm{Cl}$ & $\begin{array}{c}\text { OR } \\
\text { Those who continued } \\
\text { to smoker during } \\
\text { pregnancy }(n=165) \text { vs. } \\
\text { non-smoker }(n=897)\end{array}$ & $95 \% \mathrm{Cl}$ \\
\hline Social status (unemployed) & $13.2^{* * *}$ & $3.90-44.79$ & $4.33^{* *}$ & $1.73-10.83$ \\
\hline Roma ethnicity & 3.52 & $0.69-17.9$ & 2.56 & $0.89-7.33$ \\
\hline Family income under 100 euros/month & $3.01^{*}$ & $1.02-8.83$ & $2.23^{* *}$ & $1.06-4.72$ \\
\hline Lack of facilities & $0.12^{* *}$ & $0.02-0.55$ & 1.55 & $0.58-4.11$ \\
\hline Lack of house ownership & 1.13 & $0.38-3.41$ & 1.61 & $0.75-3.45$ \\
\hline Education below level of high school & 0.81 & $0.26-2.48$ & 0.81 & $0.29-2.24$ \\
\hline Weekly alcohol consumption & 1.26 & $0.12-3.56$ & $14.5^{\star \star \star}$ & $4.97-39.6$ \\
\hline Coffee intake $>2$ cups/day & 0.62 & $0.21-1.81$ & 1.70 & $0.83-3.48$ \\
\hline Lack of regular exercise & 1.31 & $0.52-3.28$ & 0.67 & $0.30-1.53$ \\
\hline
\end{tabular}

${ }^{*} \mathrm{p}<0.05,{ }^{* *} \mathrm{p}<0.01,{ }^{* * *} \mathrm{p}<0.001$

who stopped smoking upon finding out about the pregnancy $(\mathrm{n}=$ 216); and women who continued smoking during pregnancy $(\mathrm{n}=$ $165)$ vs. non-smokers $(n=897)$. Women who were unemployed $(\mathrm{OR}=13.2,95 \% \mathrm{CI}: 3.90-44.79)$ and women with facilities in households smoke more during pregnancy $(\mathrm{OR}=0.12,95 \% \mathrm{CI}$ : $0.02-0.55)$. Family income under 100 Euros/month during pregnancy had higher odds of smoking during pregnancy vs. quitting $(\mathrm{OR}=3.01,95 \% \mathrm{CI}: 1.02-8.83)$ and vs. being a nonsmoker (OR $=2.23,95 \%$ CI: $1.06-4.72$ ). Women who consumed alcohol during pregnancy had higher odds of smoking during pregnancy vs. being a nonsmoker $(\mathrm{OR}=14.5,95 \% \mathrm{CI}$ : 4.97-39.6). There was no association between pre-term gestation and physical activity and smoking status during pregnancy.

\section{DISCUSSION}

In the former communist countries of Central Europe, prevalence of smoking among females rose after the transition from centralized to market economies. In Romania, the increase was dramatic, rising from $11 \%$ to $25 \%$ between 1989 and 2000 (10, $18,19)$. The prevalence of smoking among women remains high in Austria and Greece (40\%), followed by Hungary and the Czech Republic (over 30\%), and lower in Croatia (4, 20, 21). Similar studies have been published on the prevalence and correlates of tobacco use among pregnant women in Romania (9, 12, 16, 22, 23 ). In our study, $30 \%$ of women smoked prior to pregnancy and $12.9 \%$ continued to smoke after they learned they were pregnant. The other Romanian studies reported smoking prior to pregnancy ranging from $24.1 \%$ in 2007 (14) to $41 \%$ in 2010 (16) and during pregnancy from $24 \%$ in 2008 (9) to $15 \%$ in 2010 (16). In a Polish study conducted in 2008, smoking rates among pregnant women were $25-30 \%$, a percentage which increased to $33-41 \%$ after applying a biochemical test for validation of nicotine metabolism (24). In Hungary, $26.1 \%$ of women continued to smoke after they found out they were pregnant (25).

Like previous studies, we observed especially high rates of tobacco use among pregnant women self-identified as Roma in unadjusted, descriptive analyses (7, 16, 22). However, Roma status was not related to smoking during pregnancy in the multi- variable model, suggesting that poor socioeconomic conditions and not ethnicity are the primary determinants of continued smoking. Tailored interventions to promote cessation that address the unique needs (and priorities) of this poor populations are needed. The association between Roma smoking women and poverty highlighted in the study of Balázs et al. (7) confirms the need for community interventions to address poverty as a key determinant of poor health outcomes in this community. The association between continuing smoking in pregnancy and low birth weight (LBW) was also highlighted by our study.

While this study adds to our scientific understanding on the prevalence and correlates of tobacco use among a sample of pregnant women in the Transylvanian region of Romania, there are important methodological limitations. Specifically, we conducted a cross-sectional survey, which limits causal inference. Moreover, we surveyed a convenience sample of women from a concentrated geographical region, which may not be representative of the population of pregnant women in Romania or the population of women of childbearing age in other Central and Eastern Europe countries.

\section{Implications for Practice and Policy}

Our data reveal a high prevalence of pregnant women who smoke daily in Romania who endanger not only themselves but also their children' health. Importantly, women who continued to smoke during pregnancy were significantly more likely to give birth to low-birth weight babies than non-smokers and quitters. Babies born with low birth weight are more likely to have significant health complications and the costs borne by the health care systems and health ministries can be extraordinary. Therefore, tobacco interventions that are evidence-based and can promote cessation among pregnant women should be a high priority $(1,26)$. For example, health providers may promote cessation by offering cessation advice and assistance, including behavioural counselling and promoting the national quit line. This will require proper training of healthcare providers including physicians, nurses, pharmacists, dentists, etc. who are taking care after pregnant women. Moreover, policy makers should prioritize cessation services by supporting the national comprehensive cessation programme through adequately staffing the national quit-line, making available pharmacotherapy 
to support cessation, and by mandating tobacco cessation training by all medical providers. Finally, policy makers are well-advised to adopt the broader goals of the Framework Convention on Tobacco Control, which Romania ratified in 2011 to ensure comprehensive tobacco practices and policies to reduce the health, social, and financial burden of tobacco-attributable disease.

\section{CONCLUSIONS}

The findings of this study suggest that smoking before and during pregnancy remains a major public health concern in Romania. The study also attempts to identify the groups of greatest risk of continued smoking during pregnancy in order to develop tailored, culturally-relevant interventions to promote cessation among pregnant women in Romania.

\section{Aknowledgements}

Research reported in this publication was supported by the Fogarty International Center and the National Cancer Institute of the National Institutes of Health under Award Number R01 TW009280. The content is solely the responsibility of the authors and does not necessarily represent the official views of the National Institutes of Health.

\section{Conflict of Interests}

None declared

\section{REFERENCES}

1. Chamberlain C, O'Mara-Eves A, Oliver S, Caird JR, Perlen SM, Eades SJ, et al. Psychosocial interventions for supporting women to stop smoking in pregnancy. Cochrane Database Syst Rev. 2013 Oct 23;(10):CD001055.

2. Cinciripini PM, Blalock JA, Minnix JA, Robinson JD, Brown VL, Lam C, et al. Effects of an intensive depression-focused intervention for smoking cessation in pregnancy. J Consult Clin Psychol. 2010 Feb;78(1):44-54.

3. WHO report on the global tabacco epidemic, 2011: warning about the dangers of tabacco. Geneva: WHO; 2011.

4. Smoking cessation interventions during pregnancy and the postpartum period [Internet]. Rockville (MD): Agency for Healthcare Research and Quality; 2013 [cited 2016 Jan 20]. Available from: http://effectivehealthcare.ahrq.gov/index.cfm/search-for-guides-reviews-and-reports/?produc tid=1423\&pageaction=displayproduct.

5. Rada C. Sexual behaviour and sexual and reproductive health education: a cross-sectional study in Romania. Reprod Health. 2014 Jun 23;11:48.

6. Arora CP, Kacerovsky M, Zinner B, Ertl T, Ceausu I, Rusnak I, et al. Disparities and relative risk ratio of preterm birth in six Central and Eastern European centers. Croat Med J. 2015 Apr;56(2):119-27.

7. Balázs P, Rákóczi I, Grenczer A, Foley KL. Birth-weight differences of Roma and non-Roma neonates-public health implications from a population-based study in Hungary. Cent Eur J Public Health. 2014 Mar;22(1):24-8.

8. Hrubá D, Kachlík P. Influence of maternal active and passive smoking during pregnancy on birthweight in newborns. Cent Eur J Public Health. 2000 Nov;8(4):249-52.
9. Moga M, Preda GH. Smoking in pregnancy. J Environ Prot Ecol. 2008;9(3):566-73.

10. Smedberg J, Lupattelli A, Mårdby AC, Nordeng H. Characteristics of women who continue smoking during pregnancy: a cross-sectional study of pregnant women and new mothers in 15 European countries. BMC Pregnancy Childbirth. 2014 Jun 25;14:213.

11. Borland T, Babayan A, Irfan S, Schwartz R. Exploring the adequacy of smoking cessation support for pregnant and postpartum women. BMC Public Health. 2013 May 14;13:472.

12. Sorina I, editor. Global adult tobacco survey - Romania 2011. Bucharest: Ministry of Health Romania; 2012.

13. Suprewicz K, Kozikowska I, Chrobaczyńska-Dylag M, Gał A, Piekarz A, Sikora J, et al. Effects of the cigarette smoking on the newborn clinical parameters and the accumulation of cadmium and lead in the placenta of women from Upper Silesia. Ginekol Pol. 2013 Sep;84(9):776-80. (In Polish.)

14. Romanian National Programe "Stop Smoking" [Internet]. Bucharest: Ministry of Health Romania; 2007 [cited 2016 Jan 20]. Available from: http://www.stopfumat.eu/despre-programul-national-stop-fumat. (In Romanian.)

15. Munteanu I, Trenchea M, Puscoiu C, Mihaltan F. Smoking prevalence of pregnant women in Romania: smoking effects on newborns. CHEST. 2007 Oct;132(4);256.

16. Meghea CI, Rus D, Dirle IA. Characteristics and health behaviors of pregnant women in Romania. GINECO RO. 2010;6(3):166-71.

17. Eriksen M, Mackay J, Ross H. The Tobacco Atlas. 4th ed. Atlanta (GA): American Cancer Society; 2012.

18. Ruger JP, Emmons KM. Economic evaluations of smoking cessation and relapse prevention programs for pregnant women: a systematic review. Value Health. 2008 Mar-Apr;11(2):180-90.

19. Ciobanu M, Bursuc B, Paunescu B. Evaluation of knowledge, attitudes and practices of Romanian adults about active and passive smoking [Internet]. Bucharest: National Institute of Pneumology Marius Nasta; 2009 [cited 2016 Jan 20]. Available from: www.ms.ro. (In Romanian.)

20. Foley KL, Balázs P, Grenczer A, Rákóczi I. Factors associated with quit attempts and quitting among eastern Hungarian women who smoked at the time of pregnancy. Cent Eur J Public Health. 2011 Jun;19(2):63-6.

21. Padjen I, Dabić M, Glivetić T, Biloglav Z, Biočina-Lukenda D, Lukenda J. The analysis of tobacco consumption in Croatia - are we successfully facing the epidemic? Cent Eur J Public Health. 2012 Mar;20(1):5-10.

22. Meghea CI, Rus D, Rus IA. Summers Holtrop J, Roman L. Smoking during pregnancy and associated risk factors in a sample of Romanian women. Eur J Public Health. 2012 Apr;22(2):229-33.

23. Meghea CI, Rus IA, Rus D. Risk factors associated with nicotine dependence in a sample of Romanian pregnant smokers. Eur J Obstet Gynecol Reprod Biol. 2012 Jul;163(1):22-6.

24. Polańska K, Hanke W, Sobala W, Jurewicz J. Exposure to tobacco smoke of pregnant women-results of prospective study in Lodz region. Przegl Lek. 2007;64(10):824-6. (In Polish.)

25. Fogarasi-Grenczer A. Socioeconomic factors of tobacco smoking during pregnancy. In: Balázs $\mathrm{P}$, editor. Increasing capacity for tobacco research in Hungary 2008-2013. Budapest: Institute for the History of Hungarian Sciences; 2013. p. 137-49.

26. Windsor R, Clark J, Cleary S, Davis A, Thorn S, Abroms L, et al. Effectiveness of the Smoking Cessation and Reduction in Pregnancy Treatment (SCRIPT) dissemination project: a science to prenatal care practice partnership. Matern Child Health J. 2014 Jan;18(1):180-90. 